American Journal of Applied Sciences 6 (6): 1235-1241, 2009

ISSN 1546-9239

(C) 2009 Science Publications

\title{
Evaluation of Damsites Groutability Using Secondary Permeability Index, Rock Classification (Case Studies)
}

\author{
R. Ajalloeian and F. Moein \\ Department of Geology, Faculty of Science, Esfahan University, 81746-72441, Esfahan, Iran
}

\begin{abstract}
Problem statement: The dam body and foundation seepage is one of the important points in design parameters. This index is related to the permeability. There fore permeability is one of the basic parameter in design grout curtain, prevent water escape from foundation and avoid negative seepage pressure in borrow materials, so grouting is used. Grouting means injected materials like cement or chemical materials under pressure to rock or soil layers. Approach: Purpose of grouting is treatment fractures, fissures, increase strength and decrease seepage. Grout curtain is used for sealing beneath dam body and other structure to obtain above aspects. Results: The present research dealing to study the geotechnical characteristics and conditions of two damsites (Kavar and Sheshpir dam) regarding to their permeability and groutability. Permeability in rock mass is controlled by jointing and their characteristics. The Kavar dam may be constructed on Gareh Aghaj river. This site is located in $40 \mathrm{~km}$ southwest of Fars province, Iran. The river flow direction is parallel to the local syncline axis. The main geological features of damsite are faults, fractures and gypsum lenses that they may lead to water escape from reservoir. The rocks in the right abutment of the dam are heavily crushed with low strength. Therefore it is expected that water escape from this zone and some parts of dam axis may happen. This is approved from boreholes logs analysis and Water Pressure Tests (WPT). The other dam which called Sheshpir is located in west of Shiraz, Iran. Regarding to structural geology of this site, two large anticlines are extended in general direction of Zagros mountain range (northeastsouthwest). The geology index features are karstic and jointed rock with faults. In general, regarding the grout-curtain design for each case, it is necessary to evaluate the volume of grout and injection system. Because of complexity of local structural geology especially rock foundation, it is difficult to estimate above-mentioned parameters. Conclusion/Recommendations: Therefore, through a number of WPT in both sites, the Permeability and hydro fracture tests results were used in the foundation for the design of the grouting program. using SPI rock classification systems, it is possible to identify the karstic features of the formation and the relationships between the permeability and groutability. This method that first expressed by foyo identify the special classification for grouting. In this system use results of Water Pressure Test (WPT) and Rock Quality Design (RQD) simultaneously. With the help of these two parameters rock class and grout complex is identified.
\end{abstract}

Key words: Water pressure test, Secondary permeability index, dam foundation, permeability

\section{INTRODUCTION}

The Kavar dam is a rock-fill dam for storage water. The dam is located in the southwest of Iran in the Fars province. It provides a barrier for water from Ghareh Aghage River. The catchment's area is approximately $1601 \mathrm{~km}^{-2}$ and the total volume of the reservoir is $242 * 10^{6} \mathrm{~m}^{-3}$. The rock mass in the foundation of the dam consist of Oligocene, Eocene and Miocene limestone and marls. The main problem of this dam is water escape from it's axe and abutments. In order to solve this problem grouting is commended. In this regard, the permeability of rocks was determined and analyzed trough about 82 Water Pressure Tests (WPT) in 6 boreholes. These tests were carried out with a single packer system. The boreholes were drilled step by step and water pressure tests were done in each section from top to bottom. The borehole diameter was $38 \mathrm{~mm}$ and the test section length is variable. On the other hand, the Sheshpir damsite as an embankment dam for storage water was investigated. This site is located in west of Shiraz, south-west of Iran. The rock masses in the foundation, which exposed in cores of anticlines, are dominantly made of the calcareous

Corresponding Author: R. Ajalloeian, Department of Geology, Faculty of Science, Esfahan University, 81746-72441, Esfahan Iran 
(Albian-Turonian period), underlain and overlain by impermeable shale (Aptian-Cenemonian period). The main structural geology features are thrust, normal and strike-slip faults which have created suitable conditions for extensive karstification. The main problem of this site is also water escape from its axe and abutments.

The determination of the permeability in a porous mass was first made possible by Darcy's law. In attempting to describe and estimate the permeability of jointed rock, the result of water pressure test should be transferred to $\mathrm{k}$ - value. Used the results of water pressure test (lugeon value) is not suitable for evaluate grouting. Because of this test can not determined permeability of rock mass correctly or local parameters related to the rock mass. To find correlation between the result of water pressure test and k-value, much more effort had been done, but till now no one is suitable. This problem will be solved by using Secondary Permeability Index method (SPI). This method use water flow absorbed by fissured rock mass, borehole radius, duration of each pressure level with other parameters and has own classification for grouting that does not need to use transformed water pressure test result to the $\mathrm{k}$ - coefficient ${ }^{[1-4,9]}$.

\section{MATERIALS AND METHODS}

In order to achieve objective, field work was carried out to get required data. Use water pressure test: lugeon and lufran, with help of rock coring for predicted permeability and groutability. Regarding to study permeability of rocks in this site, about 195 water pressure tests in 10 boreholes was done and analyzed $1500 \mathrm{~m}$ rock core were drilling and investigated ${ }^{[4-6,8]}$.

Secondary Permeability Index (SPI): Usually, the secondary permeability of fissured rock masses is expressed from the conversion of the take of water pressure test into a permeability coefficient analogous to porous mass. Secondary Permeability Index (SPI) is defined as follow ${ }^{[7]}$ :

$$
\mathrm{SPI}=\mathrm{C} \frac{\operatorname{Ln}\left(\frac{2 \mathrm{le}}{\mathrm{r}}+1\right)}{2 \pi \mathrm{le}} \times \frac{\mathrm{Q}}{\mathrm{Ht}}
$$

SPI = Secondary permeability index, $1 \mathrm{sec}$ per $\mathrm{m}^{2}$ of borehole test surface

$\mathrm{C}$ = Constant depending upon viscosity, for an assumed temperature of rock at $10^{\circ} \mathrm{C}$, $\mathrm{C}=1.49 \times 10^{-10}$

le $=$ Length of the test section, $(\mathrm{m})$

$\mathrm{r} \quad=$ Borehole radius, $(\mathrm{m})$
$\mathrm{Q}$ = Water flow absorbed by fissured rock mass, 1

$\mathrm{t}=$ Duration of each pressure level, $\mathrm{s}$

$\mathrm{H}=$ Total pressure expressed as water column, $\mathrm{m}$

According to the Foyo et al. ${ }^{[7]}$ four type of Pt-SPI graph are recognized. These graphs are as followed:

Graph type A: Absence of rock mass quality modification.

Graph type B: Washout of the in-fill process.

Graph type C: Hydraulic fracturing manifested as splitting. The joint opening is irreversible and at descending pressures the SPI value is higher than ascending pressures, It is very important to consider this process is occurred because the rock mass quality of the test section is reduced by the test development. As a result it is important that the test reflects an important SPI increasing at descending pressures.

Graph type D: Clogging. Type D implies the sealing of the fissures by removal of an existing in-fill in the test section.

Another type of graph that has been seen in research is called dilation or hydraulic jack and we placed it as a type of graph, type C.2. ${ }^{[7]}$.

Graph type C.2:

Dilation: The joint opening is reversible and the SPI value is similar or lower so at descending as at ascending pressures because the rock mass conditions are recovered when the pressure is decreased. The test reflects an important increasing of the SPI value at higher pressure than maximum pressure and the recovering of the initial conditions at the end of the test. For example, water pressure test result of K115-T5 exemplifies this and can be considered representative of the curve morphology (Fig. 1) ${ }^{[4,5]}$.

The importance of this method (SPI) is possibility to distinguish difference between dilation and hydraulic fracturing. These two behavior are so different, one of them, hydraulic fracturing is occurred at the plastic manner and the other one, dilation is occurred in elastic manner. Houlsby 1990 proposes the process of dilation when at the maximum pressure level the water absorption is much higher than the remainders levels. The pattern of values shows in Fig. 2. The peak pressure produces a much higher lugeon value than before or after it. This pressure has been sufficient to locally dilation cracks by compression of softer materials or by closure of adjacent parallel cracks. 

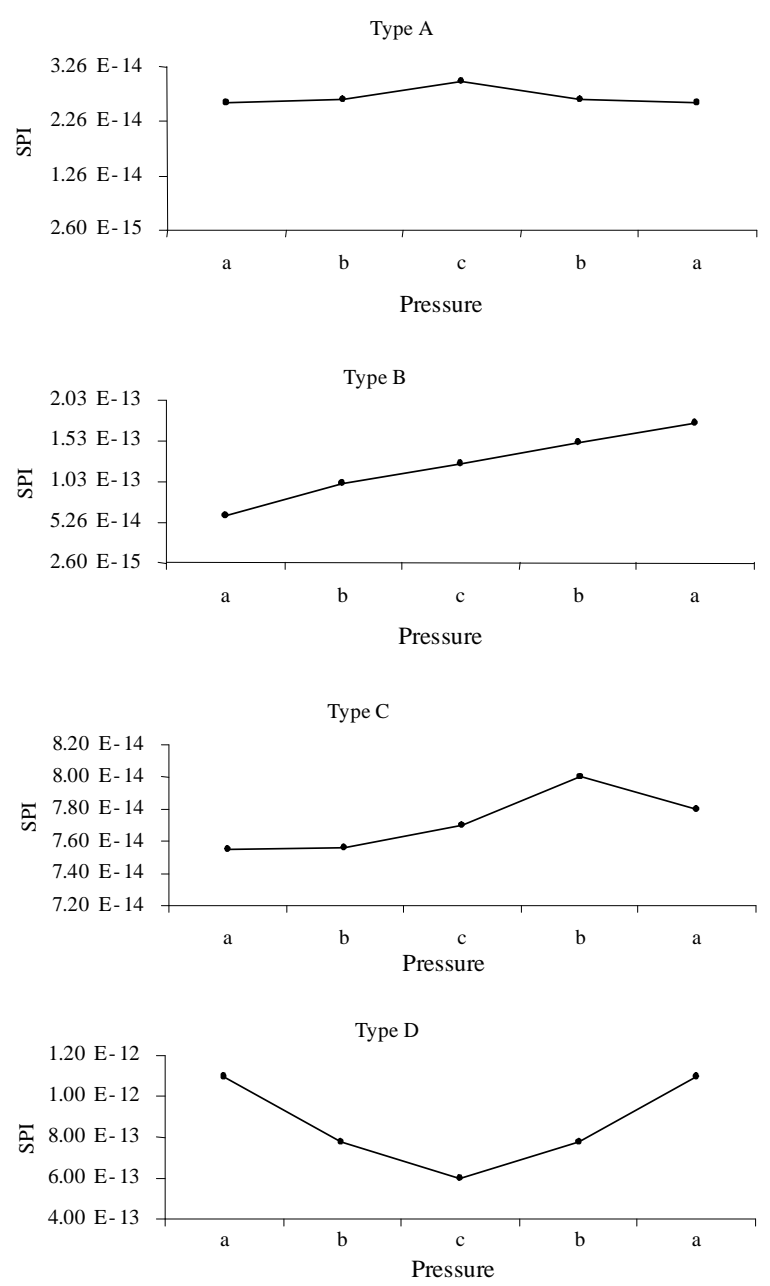

Fig. 1: Difference type of Pt v. SPI ${ }^{[6]}$

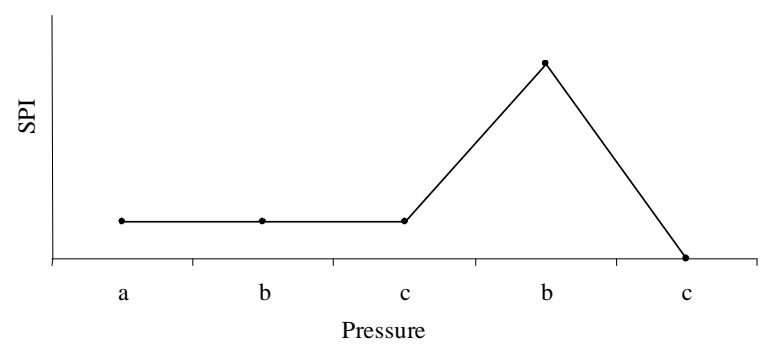

Fig. 2: Dilation condition at higher pressure

The dilation has been temporary and for this reasons the reported permeability of the stage should be that obtained for the lowest pressure, or alternatively for the medium pressure if these are less than for the low pressure, indicating that turbulent flow was occurring prior to the dilation (7). With attention to the
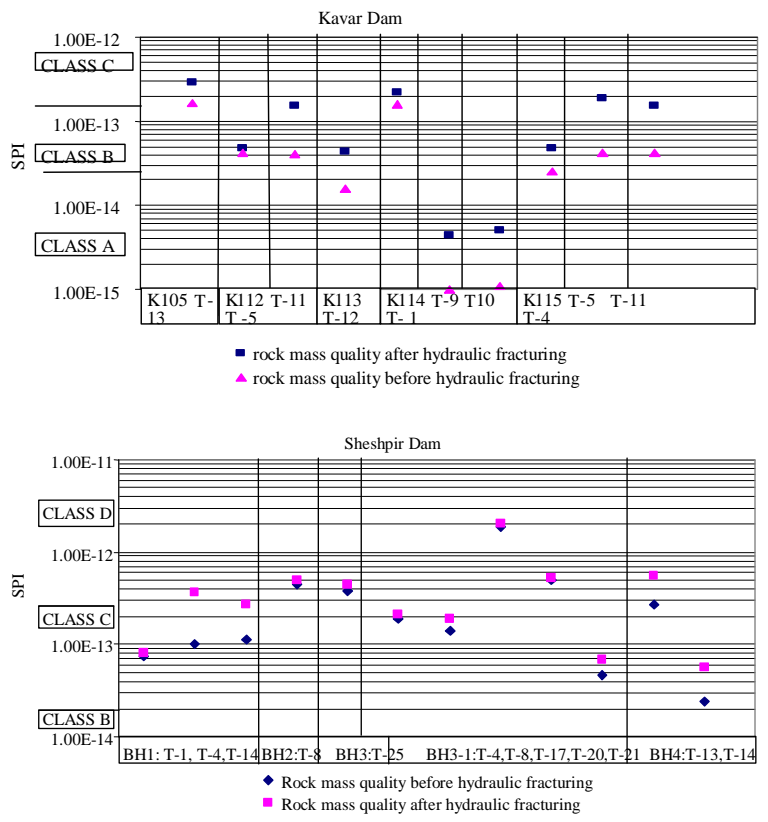

Fig. 3: SPI application (Degree of modification in Kavar and Sheshpir projects)

1type c) it is reveled that difference between two manner (hydraulic fracture and dilation) is very important especially when grout treatment is required, because with use of water pressure test it is not possible to distinguish between them. During grouting if dilation occurred, ground treatment is operated better than usual because: (1) ground treatment is done in elastic manner therefore the rock mass quality is not reduce and (2) permeability after test is reduce and these are the aim of grouting ${ }^{[7]}$.

In order to qualifying the hydraulic fracture and its rate, different section of boreholes were examined. Two grades can be distinguished from water pressure test realized in the Kavar and Sheshpir dams (Fig. 3).

Small deterioration: The decreasing caused by the hydraulic fracturing does not move the rock mass quality to an inferior order (K112 T-5, K114 T-1 in Kavar dam) and (BH1 T-1, BH3-1 T-4, T-20 in Sheshpir dam).

Intense deterioration: Consequently with the joint opening and continuity amount, the SPI shows gently deterioration in the quality of the test section. This grade implies the transit to inferior class order (K113 T12, K114 T-10 and K115 T-11 in Kavar dam) and (BH1 T-4, T-14 in Sheshpir dam). With attention to the figure discover that hydraulic fractures grade (a) is dominant 
behavior that is shows new joints are not formed and grade $b$ is shows that the existing joins are extensive.

The grout pressure, composition and rock mass strength is determined after distinguished hydraulic fracturing grad. With help of Fig. 3 it is obvious that the pressure is suitable (in both test) but probably the hydraulic fracture is happened during grouting. While grouting the higher pressure is used and because of low strength rock, the hydraulic fracture is not avoidable. To prevent this event especial method of grouting should be used.

As an example of hydraulic fracture, the result of water pressure test which carried out in borehole K115, T-5 has been explained (Fig. 4).

Even in the grade a the difference between hydraulic fracture and dilation is reveled. Because of the reduction in rock mass quality is occurred and this is the hydraulic fracturing characteristic.

Water pressure test carried out in the borehole K115 T-5 is an example of hydraulic fracture (Fig. 4). The hydraulic fracturing phenomenon appears once 6.47 bar of total pressure is exceeded. The test can not be completed and it is necessary to reduce the pressure. The SPI shows a little increase at descending pressure, which indicates not very important rock mass quality decreasing. Following the criteria exposed by Foyo et $a l^{[7]}$ the SPI value associated with the critical pressure defines the rock mass quality, 7.55E-14 1 $\sec ^{-1} * \mathrm{~m}^{-2}$ class B, good-fair. The deterioration induced by the test is determined by the maximum SPI value obtained at descending pressure, $8.00 \mathrm{E}-131 \mathrm{sec}^{-1} * \mathrm{~m}^{-2}$ class $\mathrm{C}$ poor (Fig. 4):

- Class B (Good-fair): Rock mass quality

- Class C (poor): Quality reduce by hydro fracturing

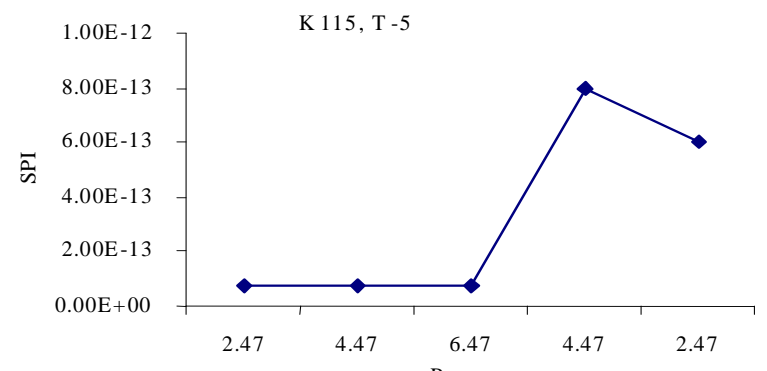

Kavar dam

borehole 115

ressure

single packer water load test

Total pressure (bar) SPI (1/s*m2)

2.47

4.47

6.47

4.47

2.47

$7.52 \mathrm{E}-14$

water absorbed $\left(1 / \mathrm{min}^{*} \mathrm{~m}\right)$

0.42

1.47

7.72E-14B $\quad 3.04$

$8.00 \mathrm{E}-13 \mathrm{C} \quad 2.62$

Fig. 4: SPI application. Hydraulic fracturing

\section{RESULTS AND DISCUSSION}

Result analysis of kavar and sheshpir dams: The rock mass classification defined by SPI and the depth of the test has been analyzed (Fig. 5). These analyses have been carried out enclosing the test in two intervals $\operatorname{depth}^{[6]}$.

Surface tests carried out at depth of less than $30 \mathrm{~m}$. Regarding to Kavar project, the results indicate mainly class D, nevertheless, a number of class B tests appear associated to the high degree of unloading. But in Sheshpir project, classes D and C are dominant. Regarding to deep zone (depth $>30 \mathrm{~m}$ ), still more or less $\mathrm{C}$ and $\mathrm{D}$ classes are present. In sheshpir project at (depth $>30 \mathrm{~m}$ ) in spite of class B and A appear, the dominant classes are $\mathrm{C}$ and $\mathrm{D}$ yet. Therefore an improvement of the rock mass quality is confirmed. This interval has been considered long enough to ensure the rock mass quality is not too increasing. It is possible that discontinuities of high permeable activity may exist.

Usually we expected that with depth increases, SPI decrease but in these two cases this is not happened. It has been many reason but two of the are stronger possibility here.

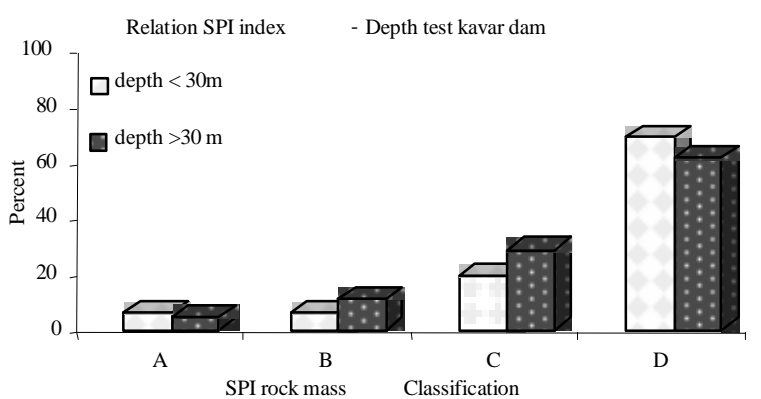

(a)

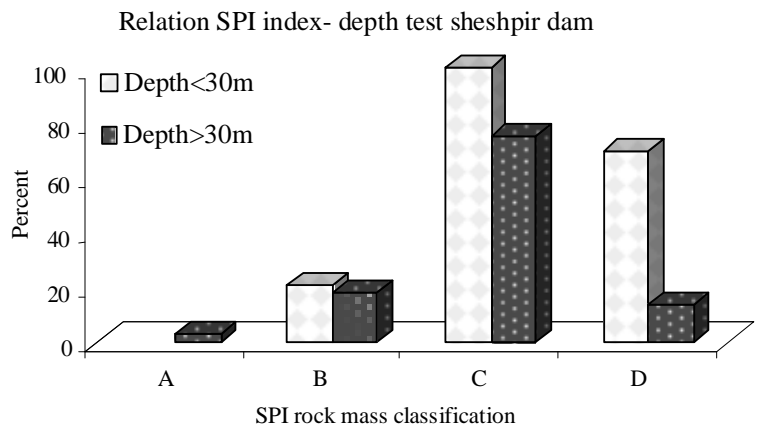

(b)

Fig. 5: Analysis of the results, depth Vs. SPI. (a): Kavar damsite; (b): Sheshpir damsite 
Karstic phenomenon: In sheshpir project some karsric drainage excite. They can be a drainage for water escape and case high value of SPI. This problem can be distinguish with help of RQD.

Faulted zone: Faulted zone crushed and fractured rock mass and filling fracture with low strength material like clay and gypsum are caused defected zone. The especial problem here is the size of joints and fracture. Some of them are so close that grout cant pass through them but water can. This zones need especial grout for example chemical one. To recognize this zone RQD and fracture description should be used too.

Comparison of the rock mass quality defines by SPI and the degree of jointing reveals the following aspect (Fig. 6):

- Less than $20 \%$ of tests (14 test from 82 in Kavar) and 15\% (15 test from 113 in Sheshpir) show an accurate correlation which indicates the important differences between rock mass quality definition from SPI and degree of jointing as defined using RQD index

- In boreholes $105,112,113,114,115$, where the SPI shows a very low rock mass quality for the surface area. It must be remembered that those water pressure tests were carried out with single packer test at ascending sequence. Nearly in all boreholes in two projects SPI shows a low rock mass quality for the surface area. Here it must remember that theses areas are in the crush and fault regions

- Those tests sections which show a (kavar dam) and T19 carried out in the BH3 (sheshpir project)low degree of jointing, but with high permeable activity as indicated by the SPI, should be noted. The t-5 test carried out in the K-105 is an example (Fig. 6). The RQD index indicates average low degree of jointing but the SPI confirms that at least one joint with a very high activity exists and with attention to the geology of the region it might because of karst drainage. In karstic region like here the relation between channels should be consider. As a result, rock mass quality of the test section is class $\mathrm{D}$, very poor. Under this conditions and following the considerations about ground treatment named previously, a thick mixture is recommended

- On the other hand, the t-3 or t-13 tests in borehole K105 (in Kavar project) represent a different situation. The SPI also shows class D and the degree of jointing is high. In this case, a thinnest mixture is required. In both cases, the Pt-SPI graphs have shown the weathering in- fill presence and are necessary to wash the test section previously. The rock mass quality of the dam foundation has been defined from SPI (Fig. 6), which allows for the determination of different zones that require a separate treatment
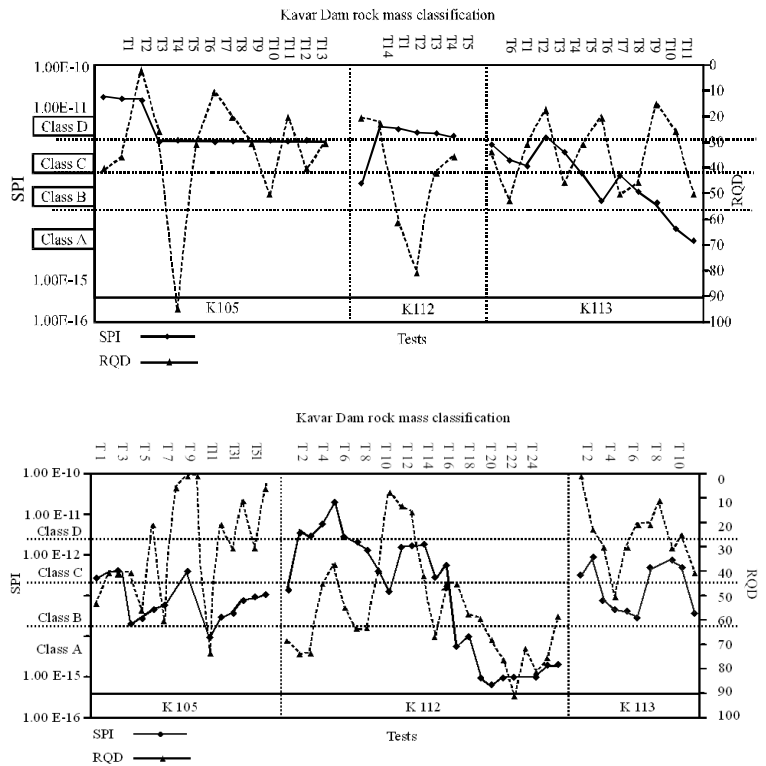

(a)
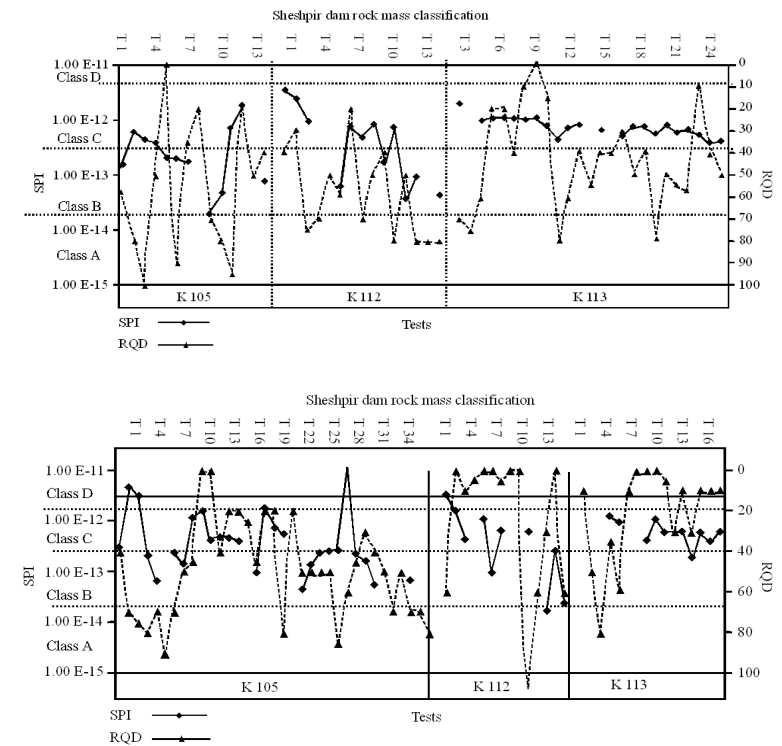

(b)

Fig. 6: Comparison between degree of jointing (RQD) and rock mass classification obtained from SPI (SPI with logarithmic scale). (a): Kavar damsite; (b): Sheshpir damsite 


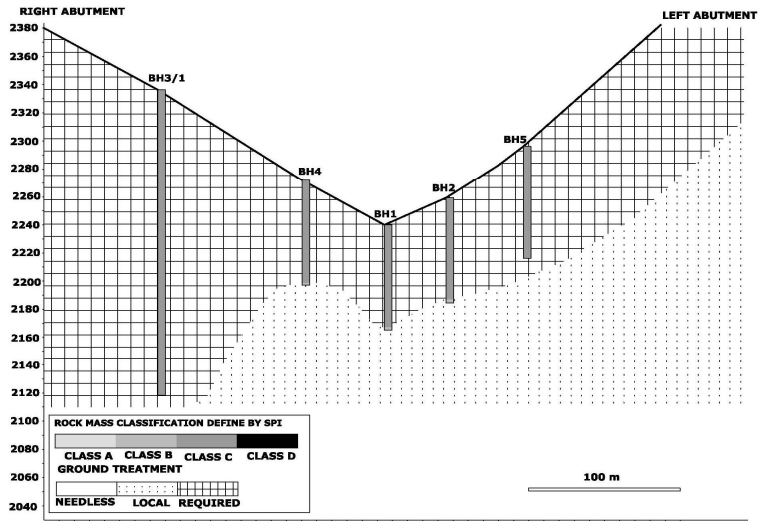

(a)

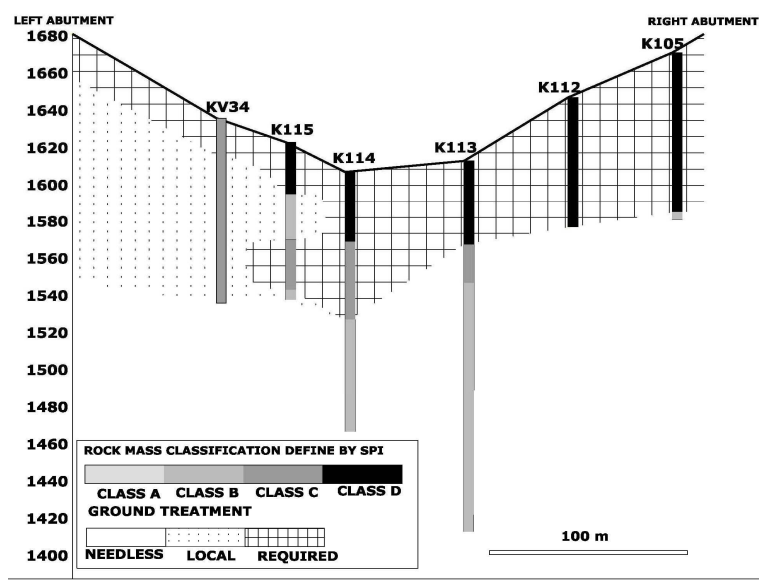

(b)

Fig. 7: Cross section of dam regarding different rock mass quality. (a): Kavar dam project; (b): Sheshpir dam project

The treatment must be done in two series (Fig. 7):

Series A: Grouting of the zones in which the SPI has indicated poor rock mass quality, class $\mathrm{C}$ and class $\mathrm{D}$. These classes are as a continuous zone that extends from the right abutment to approximately the middle of the kavar dam sit. This continuous zone extends until some part of left abutment. This zone is deducted from the results of $\mathrm{K} 105 \mathrm{t}-1$, $\mathrm{t}-12$ water pressure tests and, taking in to account a security boundary. It seems prudent to extend it to the middle of the dam. Nevertheless, the small area of the right abutment is clearly confirmed from the results of K115 T-1, t-2 and t-7 to t-10 water pressure tests. In the Sheshpir project these classes extended as a continues zone from right to left abutment. In this series, the grouting can be done in water pressure test boreholes and taking in to account the reduced opening of the joints. It seems advisable to grout a thin mixture with maximum penetration capacity, 3:1.W/C.ratio. Even though, the zone located in the left abutment between boreholes K114 and KV34 (in Kavar damsite) must be checked with additional water pressure tests. The Pt-SPI graphs of the water pressure test $\mathrm{t} 1 \mathrm{-t} 12$ carried out in the borehole K105 has shown the presence of clogging of the in-fill. Therefore, washing of the test sections before grouting is recommended.

Series B: Grouting corresponds to the sealing of the test zones where SPI has indicated that a local treatment is required. Class $B$ with the degree of jointing is medium-low (Fig. 7). This criteria is exclusively fulfilled by the K105 T-13(in Kavar damsite) test sections. Nevertheless, as a security measure, those test sections in which the degree of jointing is high but the Pt-SPI graph showed the presence of weathering clogging of the infill. These are included K113 T-8 to T-9, K115 T-3 to T-6, T-10 and KV34 T-1 toT-16 (in Kavar damsite) and BH1 T-10 to T-13 and BH4 T-10 to T-13 (in Sheshpir dam). There for, the test sections must be sealed with a medium mixture $1: 1 \mathrm{~W} / \mathrm{C}$ ratio and the rest with a thinnest one, 3:1 W/C ratio. However, the presence of weathering clogging of the in-fill requires the washing of these test sections before grouting.

Finally, it is recommended one additional borehole with water pressure test at right and one at left abutment before KV34 and K112 become deeper at least 40$50 \mathrm{~m}$. On one hand, these new water pressure tests will verify the continuity of the area described in series A and $\mathrm{B}$. on the other hand, subsequently, they will be used for grouting works.

\section{CONCLUSION}

It is no doubt to use water pressure test before grout designation. Evidently, the grout properties are different from water. Water can flow through fissures inaccessible for a grout mixture. Usually, the grouting of the dam foundation requires that the rock mass be previously divided in zones with different ground treatment. The Secondary Permeability Index (SPI), based on water flow trough fissures and allows zoning the dam foundation regarding different quality classes $^{[6]}$.

From water pressure test carried out in the Kavar and Sheshpir dam projects, it is possible to delimit the zones of the dam foundation that shows different rock mass quality. At the same time, it is possible to design a ground treatment conformable to the particularities of each zone. The analysis of the results of both dam 
revealed great difference between SPI and degree of jointing exist in some boreholes. For example KV34 (in Kavar dam) shown good fair rock mass quality from SPI but presence high degree of jointing and rock mass improvement requires only local treatment. Under this condition, a thin mixture is the best solution. On the other hand, the accurate grouting is conditioned by either presence or absence of weathering clogging in the test section. The Pt- SPI graph allows for detecting it before grouting. It is always necessary to wash the injection chamber.

\section{ACKNOWLEDGMENT}

I would like to express my gratitude to Dr. M. Sa'nchez for his valuable guidance, review and correction.

\section{REFRENCES}

1. Barton, N.R., R. Lien and J. lunde, 1974. Engineering classification of rock masses for the design of tunnel suppor't. Rock Mech., 6: 189-239. DOI: 10.1007/BF01239496

2. Bieniawski, Z.T., 1976. Rock mass classification in rock engineering. Proceeding of the 8th US Symposium on Exploration for Rock Engineering, (SERE'76), Cape Town: Bulkema, pp: 97-106.
3. Dalmalm, T., 2004: Choice of grouting method for jointed hard rock based on sealing time predictions. http://www.diva-portal.org/kth/abstract.xsql?dbid=3791

4. Ewert, F.K., 1985. Rock Grouting with Emphasis on Dam Sites. Springer Verlarg, Berlin, New York, ISBN: 3-540-15252-0, pp: 428.

5. Ewert, F.K., 1997. Permeability, Groutability and grouting of rocks related to dam sites. Part 2. Dam Eng., 8: 123-176.

6. Foyo, A. and C. Tomillo, 1997. Permeability and Groutability of the Valparaiso dam foundation. Eng. Geol., 46: 157-174. http://cat.inist.fr/?aModele=afficheN\&cpsidt=2765697

7. Foyo, A., M.A. Sa'nchez, C. Tomillo, 2005. A proposal for secondary permeability index obtained from water pressure test in dam foundations. J. Geo. Eng., 77: 69-82. http://cat.inist.fr/?aModele $=$ afficheN\&cpsidt $=1645$ 8896

8. Kutzner, C., 1996. Grouting of Rock and Soil. Illustrated Edn., Taylor and Francis, Netherlands, ISBN: 9054106344, pp: 271.

9. Weaver, K., 1991. Dam Foundation Grouting. American Society of Civil Engineering, USA., ISBN: -10: 0872627926, pp: 178. 